\title{
A inter(trans)disciplinaridade no jogo educacional de construção de cidades Città
}

\author{
Armando Zavala, PGIE/UFRGS, zavalove@live.com \\ Margarete Axt, PGIE/UFRGS, maaxt03@gmail.com
}

Resumo: O artigo apresenta uma experiência sobre o uso do jogo educacional de construção de cidades Città, como elemento disparador na realização do trabalho interdisciplinar $e$ transdisciplinar no currículo de ensino secundário em Moçambique. O jogo está em consonância com uma proposta ético-político pedagógica e de aplicação aberta a diferentes contextos educacionais, a uma proposta ambientalmente sustentável que estimula a resolução no coletivo, de problemas ou temas sociais complexos. São apresentados no trabalho, os resultados de um estudo realizado com alunos da $8^{a}$ classe do ensino secundário, aplicando-se os recursos que o jogo apresenta para discutir e propor soluções alternativas de temas complexos que não são tratados em uma única disciplina. Os resultados do estudo demonstraram que o uso do jogo, apoiado pela metodologia ativa do Projeto CIVITAS, pode ser uma alternativa tecnológica com potencial para fazer um trabalho interdisciplinar e transdisciplinar no currículo de educação formal.

Palavras-chaves: simulador città, interdisciplinaridade, transdisciplinaridade.

\begin{abstract}
The article presents an experience about the use of the educational game of city construction Città, as a triggering element in the accomplishment of interdisciplinary and transdisciplinary work in the secondary education curriculum in Moçambique. The game is in line with a pedagogical ethical-political proposal and application open to different educational contexts, an environmentally sustainable proposal that stimulates collective resolution of problems or complex social issues. The results of a study carried out with grade 8 secondary school students are presented in this paper, applying the resources that the game presents to discuss and propose alternative solutions of complex subjects that are not treated in a discipline. The results of the study demonstrated that the use of the game, supported by the active methodology of the CIVITAS Project, may be a technological alternative with the potential to do an interdisciplinary and transdisciplinary work in the formal education curriculum.
\end{abstract}

Keywords: simulator città, interdisciplinarity, transdisciplinarity.

\section{Introdução}

O simulador de cidades Città no contexto dos jogos educativos é uma ferramenta potente para o ensino e aprendizagem, quando bem integrado no currículo de educação formal (AXT et al, 2008). Pois, segundo os autores, para além de educar, possibilitando a (con)vivência e a formação de valores como cooperação, solidariedade, reciprocidade, capacidade expressiva e de escuta, incluindo o desenvolvimento atencional-cognitivo, potencializando a construção de conhecimentos; tem a componente "imaginação". Imaginação estimula a aprendizagem, incitando 
a resolução dos problemas ou temas sociais que por serem muito complexos não podem ser tratados numa única disciplina; como também estimula as capacidades cognitivas e atencionais dos jogadores bem como desenvolve a sua coordenação motora e reflexiva, abrindo espaço às possibilidades de problematização das realidades em jogo, o que permite-lhe amplificar o leque das virtualidades de (con)viver, pensar e criar.

Assim, este estudo traz uma experiência feita com os alunos da $8^{\mathrm{a}}$ classe em Moçambique, na qual fez-se um trabalho interdisciplinar e transdisciplinar no currículo deste nível de ensino, através dos recursos presentes no simulador de cidades Città, apoiados pela metodologia ativa do Projeto CIVITAS ${ }^{1}$.

CIVITAS é, na verdade um projeto que tem expectativa de poder pensar-sentir-pesquisar a Cidade Viva, em conjunto (pesquisadores, professores e crianças), numa relação de acolhimento à diversidade de posições e aos tempos de construção de conhecimento, inaugurando uma aprendizagem pautada na produção coletiva de sentidos e pela reciprocidade. Pretende construir ao lado de outros, um espaço alternativo de acontecimento-invenção na escola (AXT, 2004).

Neste trabalho, propõe-se aqui a resolução de problemas ou temas sociais complexos tratados entre as disciplinas, onde a partir dos recursos do Città, os alunos em grupos ou individualmente foram desafiados a refletir sobre o conteúdo apresentado. Servindo o Simulador como uma ferramenta disparador, organizador e norteador de ideias.

\section{Simulador Città}

O simulador de cidades Città é um jogo educacional de construção de cidades, desenvolvido no âmbito do Projeto CIVITAS, de responsabilidade do grupo de pesquisa do Laboratório de Estudos em Linguagem, Interação e Cognição (LELIC) da Universidade Federal do Rio Grande do Sul (UFRGS).

O Città ${ }^{2}$ teve a sua primeira versão desenvolvida em 2003 utilizando como suporte um editor gráfico em formato Virtual Reality Modeling Language (VRML). Este software era formado por dois módulos principais: o cliente que representa a interface de cada usuário e o servidor que é responsável por repassar as informações de um cliente a todos os outros, assim como controlar login $\mathrm{x}$ de usuários, etc. Um protótipo da interface 2D cliente foi desenvolvido em Java a fim de validar a interface deste com as crianças.

Em $2009^{3}$ teve a sua segunda versão do Città em Java e sendo um software livre com licença GPL. Atualmente (2011-2017), o Città foi reprogramado em linguagem Blender4. Esta

\footnotetext{
${ }^{1}$ Cidades Virtuais e Tecnologias para Aprendizagem e Simulação

${ }^{2}$ Projeto Città Cosmopolia. Disponível em: 〈http://cosmopolita.conexum.com.br/ >, acesso em: 16 de maio de 2017

${ }^{3}$ Projeto Città Cosmopolia. Disponível em: 〈http://cosmopolita.conexum.com.br/>, acesso em: 16 de maio de 2017 4 Blender - O Blender é uma ferramenta de modelagem e edição de objetos em dimensões e também é utilizado para a criação de animações gráficas. Sua licença livre permite que seja utilizada para o desenvolvimento de modelos, animações e jogos sem fins lucrativos como no caso do Città. Um recurso recentemente adicionado foi o motor de jogos, o qual está se utilizando para o desenvolvimento do simulador de cidades Città (MÜLLER et al. 2014).
} 
última versão caracteriza-se por ser um ambiente virtual 3D para a construção de cidades virtuais, em uma arquitetura cliente/servidor e multiusuário, e roda em Windows, Linux e Mac, além de terem sido desenvolvidos plugins para rodar um arquivo Blender em navegadores web, como o Burster4, e o Blender player para Android, o que permite, também, a execução em dispositivos móveis.

Alguns dos recursos deste jogo educacional de construção de cidades (AXT et al. 2008) podem ser descritos, sistematicamente, nos itens a seguir:

\section{Classe Câmera}

Câmera em primeira pessoa - o jogador tem a visão pela perspectiva de um personagem e pode andar pela cidade em uma simulação de um ponto de vista de uma pessoa caminhando.

Câmera em terceira pessoa - o jogador observa a cidade numa visão aérea. Essa visão habilita o jogador a operar no jogo, incluindo, excluindo e editando estruturas

\section{Classe de construção}

O modo construção é ativado através de uma opção no menu. É a função que permite incluir objetos no jogo. Os objetos (casa, prédio, indústria, etc.) são selecionados no menu, inseridos e posicionados no mapa.

\section{Classe terreno}

O terreno do jogo é uma matriz de duas dimensões da classe e estrutura, onde cada posição dessa matriz possui uma série de atributos como inclinação, direção, altura e tipo de textura.

\section{Interface Gráfica para o Usuário (GUI)}

Agrega todas as áreas da tela do jogo como menus e o ambiente 3D. Através da GUI o usuário se comunica com o jogo. A GUI é responsável por detectar as ações e o posicionamento do jogador e encaminhar a informação para as funções adequadas.

\section{Classe Editor Terreno}

Esta classe é responsável pela edição do terreno (relevo) e construção de loteamentos, de forma que se tenha um mapa de jogo com as características geográficas regionais.

A figura 01 que se segue mostra a tela inicial do simulador Città, cuja a sua versão está disponível em: http://sourceforge.net/projects/civitas/, e está sendo utilizada enquanto recurso pedagógico, pelas turmas que trabalham com a metodologia proposta pelo Projeto CIVITAS. 
Figura 01: Tela inicial do Città

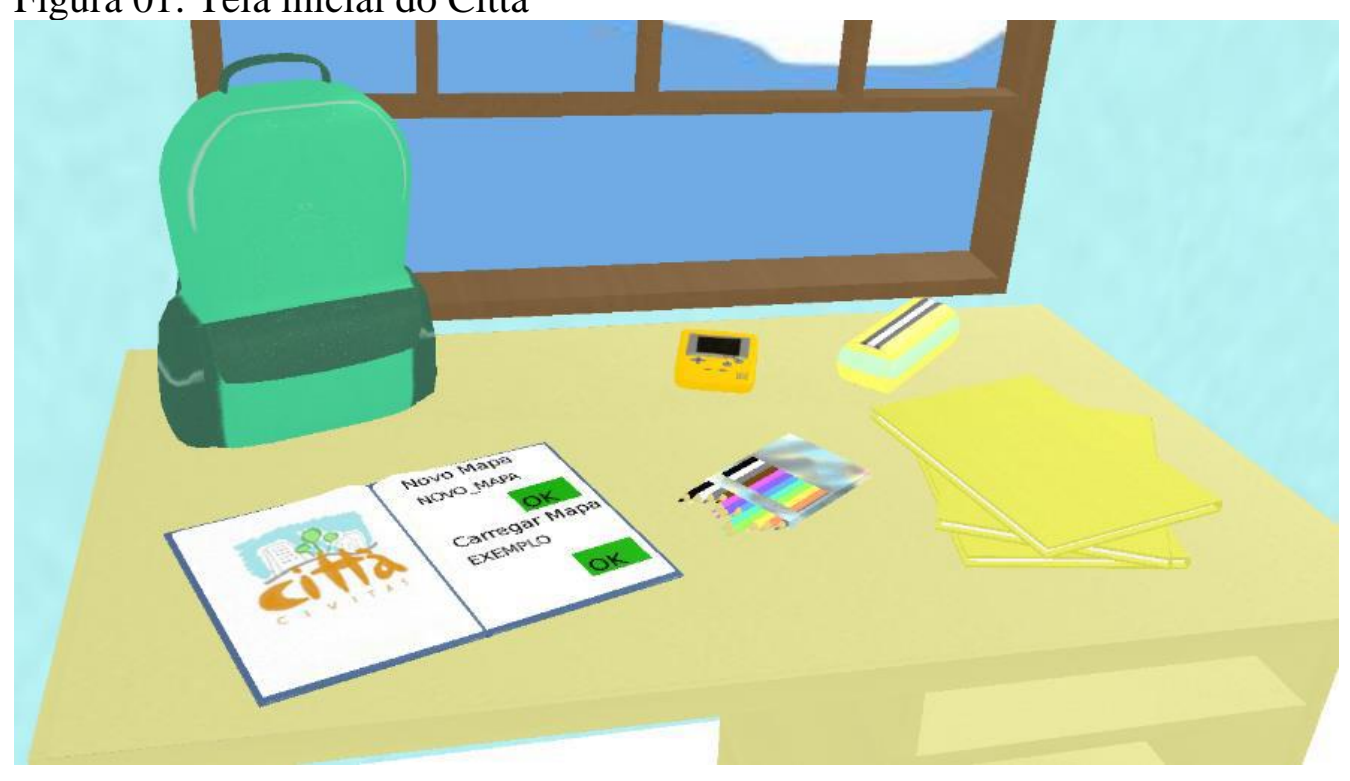

Fonte: http://sourceforge.net/projects/civitas/

Entretanto, dentro deste Projeto CIVITAS, o Città é uma ferramenta de inclusão digital a serviço de propostas ativas numa perspectiva ético-estético. À medida que o aluno vai simulando cidades virtuais pelo editor Città, aprende (para além do desenvolvimento atencional-cognitivo), pela vivência relacional com os seus pares; a tomar decisões de valor axiológico, tendo em vista um coletivo; e pelo exercício de imaginação, aprende a inscrever-se expressivamente.

Por isso, este jogo educacional de construção de cidades, o Città, é contextualizado por Müller et al (2008) a partir de Huber (2008) dentro da linha de jogos de civilização, onde o jogo proporciona a conquista do espaço e construção da infraestrutura necessária para a subsistência da população. Mas temos conhecimento de outros simuladores próximo ao Città, e que poderiam ser adaptados às necessidades educativas curriculares e inter(trans)disciplinares, mas os desconsideramos neste estudo, tanto por serem comerciais, quanto por terem embutida uma lógica competitiva em detrimento da cooperação. São os casos de Simcity ${ }^{5}$, Caesar ${ }^{6}$ ou Pharaoh ${ }^{7}$ (ambos da Impressions Games).

O Città é um software multiusuário que agrega recursos que ao ser utilizado pode contribuir para aprendizagens voltadas a problemáticas das cidades e de cidadania, na perspectiva de um coletivo auto-sustentável, pro-ativo, e cooperativo (AXT, et al. 2008). Na mesma dimensão multiusuário, acontece a participação de mais de um jogador, concomitantemente, o que proporciona a interação, tanto de maneira direta pela convivência entre os parceiros do jogo, quanto indireta entre os jogadores em forma de cooperação ou colaboração.

\footnotetext{
${ }^{5}$ SIMCITY. Disponível em: 〈http://www.simcity.com/ >, acesso em: 16 de maio de 2017

${ }^{6}$ CAESAR. Disponível em: <http://www.gamespot.com/caesar-iv/ >, acesso em: 16 de maio de 2017

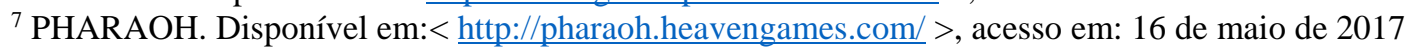


Assim, entendemos que a utilização do jogo educacional de construção de cidades, o Città, tem maior necessidade de abordagens interdisciplinares e transdisciplinares, particularmente no âmbito escolar.

\section{Interdisciplinaridade e transdisciplinaridade no simulador Città}

A interdisciplinaridade apresenta-se, a partir dos anos de 1960, como percursora na busca de respostas aos limites do conhecimento simplificador, dicotômico e disciplinar da ciência moderna ou clássica. Ela passa, então, a construir, em função de sua proposta, um modo inovador de produção de conhecimento científico, e é considerada, ao mesmo tempo, alternativa e complemento do modo disciplinar do pensamento (ALVARENGA et al., 2005).

Capes (2008) coloca a interdisciplinaridade como espaço privilegiado, como decorrência de sua própria natureza transversal indicada pelo seu prefixo (como princípio geral), para avançar além das fronteiras disciplinares, articulando, transpondo e gerando conceitos, teorias e métodos, ultrapassando os limites do conhecimento disciplinar e dele se distinguindo por estabelecer pontes entre diferentes níveis de realidade (em relação a dado fenómeno complexo), diferentes lógicas e diferentes formas de conhecimento (presentes no âmbito das disciplinas).

Por isso, Piaget (1972) considera a interdisciplinaridade como um segundo nível de colaboração entre disciplinas diversas, ou entre setores heterogêneos de uma mesma ciência que conduz a interações propriamente ditas, isto é, certa reciprocidade dentro das trocas, de maneira que aí haja um total enriquecimento mútuo.

Por sua vez, a transdisciplinaridade como uma etapa superior, assim descrita por Piaget: "Enfim, na etapa das relações interdisciplinares, pode-se esperar ver suceder uma etapa superior que seria transdisciplinar, a qual não se contentaria em atingir as interações ou reciprocidades entre pesquisas especializadas, mas situaria essas ligações no interior de um sistema total, sem fronteiras estáveis entre as disciplinas" (p. 144).

Assim, consideramos que a problematização de temas sociais relacionados aos problemas complexos de uma cidade que nos desafiam no campo da ciência, podemos, em resposta, fazer um trabalho inter(trans)disciplinar. Aliás, os recursos do Città, embora simples em si mesmos, abrem espaços para problematizações relacionadas às cidades, assim como para problemas ou temas sociais que, por serem muito complexos, não podem ser tratados numa única disciplina. A natureza de tais problemas (CAPES, 2008), pedem diálogos não só entre disciplinas, dentro da mesma área de conhecimento, mas entre disciplinas de áreas diferentes, bem como entre saberes disciplinares, não disciplinares da sociedade e das culturas, dependendo do nível de complexidade do fenómeno a ser tratado. Daí a relevância de novas formas de produção do conhecimento que tomam como objeto fenômenos que se colocam entre fronteiras disciplinares, quando a complexidade do problema requer diálogo entre e além das disciplinas.

Por isso, a interdisciplinaridade e a transdisciplinaridade no simulador Città pode ser pensada por Follari (1995) como uma possibilidade de quebrar a rigidez dos compartimentos em que se encontram isoladas as disciplinas dos currículos escolares. No entanto, segundo o autor, deve ser revista como uma etapa superior das disciplinas, disciplinas essas que se constituem como 
um recorte mais amplo do conhecimento em uma determinada área. Este recorte tem o objetivo de possibilitar o aprofundamento do seu estudo. Por exemplo, o Città pode abrir espaço para histórias inventadas ou vividas na cidade real, ou na do jogo, podendo ser exploradas nas disciplinas curriculares de história, geografia, matemática, biologia, etc.

Daí que, a utilização do jogo digital educacional de construção em sala de aula como atividade interdisciplinar e transdisciplinar, pode auxiliar muito no aprendizado dos alunos, que tem a oportunidade de pensar a realidade como um todo integrado. No caso concreto do simulador Città, há possibilidades em desenvolver esse aprendizado de forma dinâmica e interativa, através dos recursos presentes nele e apoiados pela metodologia ativa proposta pelo CIVITAS- que consiste numa intervenção, pelo viés da in(ter)venção (ou seja, uma intervenção inventiva) pensada desde 1998 pelo grupo de pesquisa do LELIC/UFRGS, cuja sua divulgação foi a partir dos escritos de Axt e Kreutz (2003), complementada por Axt (2008) e Axt (2011) como a invenção de um ato único, que acontece vinculado a um espaço-tempo, pertinente ao contexto para o qual foi inventado, adotando uma abordagem dialógica baseada no princípio de alteridade (eu-paramim, eu-para-o-outro e o-outro-para-mim) proposto por Bakhtin (2003). Sendo assim, a inter(trans)disciplinaridade apresenta-se como forma alternativa, complementar e inovadora do ensino através do Città.

Então, fazer um trabalho inter(trans)disciplinar com o Città implica não apenas com relação a fornecer as condições para que os professores naveguem através da diversidade epistemológica das disciplinas, mas para que possam ir além das suas disciplinas através de métodos ou estratégias que articulam distintos conhecimentos, o que a seguir descrevemos.

\section{Trabalho inter(trnas)disciplinar com o simulador Città}

Com os diversos recursos que o jogo educacional de construção de cidades, o Città apresenta, fez-se um trabalho interdisciplinar e transdisciplinar na Escola Secundária Quisse Mavota- Cidade de Maputo, Moçambique, durante as aulas semanais na disciplina de Tecnologias de Informação e Comunicação (TIC). O mesmo envolveu 52 alunos (uma turma) da $8^{\mathrm{a}}$ classe, num período de três meses (fevereiro a abril de 2017).

Com base no pressuposto dialógico e alteritário $^{8}$, e apoiado pela metodologia ativa do Projeto CIVITAS ${ }^{9}$, os alunos receberam orientações coletivas na sala de aulas, tendo em vista trabalhos individuais ou em grupos de dois ou três, sobre as políticas públicas sustentáveis a partir dos problemas (ou temas sociais) que assolam a Cidade de Maputo. Os temas de discussões foram propostos pelo coletivo (alunos e pesquisadores), o que contribuiu para o processo de problematização pelo grupo, na relação dialógica-alteritária estabelecida na cena de pesquisa.

\footnotetext{
${ }^{8}$ Bakhtin (2003) evidencia o dialogismo e alteridade nas pesquisas em ciências humanas e propõe a existência de duas consciências, dois sujeitos (eu/pesquisador e outro/pesquisado). Portanto, neste estudo houve uma interação dialógica nossa com o aluno onde o aluno respondeu a nós, assim como interação dialógica entre os próprios alunos em que um respondia ao outro.

${ }^{9}$ No Projeto CIVITAS são aplicadas novas metodologias que utilizam diferentes tecnologias que coexistem na sala de aula.
} 
Com as discussões, os alunos instigados pelo jogo de construção, pensaram e problematizaram a realidade na qual estão inseridos e propuseram alternativas de soluções para a ultrapassagem dos problemas, as quais se atualizaram, no jogo, em narrativas urbanas coletivas. Concomitantemente, utilizando o jogo educacional de construção de cidades, o Città, os alunos simularam cidades digitais que contenham estas problematizações e propostas de soluções discutidas.

Nestas discussões, os alunos foram levantando problemas ou temas sociais complexos que para obterem as propostas soluções, teve que se recorrer à cooperação entre as disciplinas a partir dos recursos do simulador Città. Eis alguns exemplos de problemas:

Quadro 1: Problema e proposta de solução apresentado pelo grupo A da pesquisa

\section{Grupo $\mathrm{A}-8^{\mathrm{a}}$ classe $\quad$ Corrupção nas instituições públicas}

Para tratar qualquer coisa nas instituições públicas é preciso subornar com dinheiro aos funcionários. Por exemplo, nos hospitais públicos se não dá algum valor ao pessoal de saúde, o seu atendimento não será dos melhores. Até nas filas para atendimento é preciso dar algum dinheiro aos serventes porque caso contrário, corre o risco de voltar para casa doente e sem ser atendido (sujeito A1).

Nas esquadras policiais se você for apresentar uma queixa, se não der dinheiro aos oficiais, eles não vão tramitar o seu expediente. Se encontrar uma pessoa que te roubou, a polícia vai soltar caso você não for pagar algum dinheiro. E a polícia come com os ladrões por isso as pessoas acabam fazendo justiça com as próprias mãos. Os linchamentos crescem cada dia que passa na cidade, devido a atitude da polícia. Por vezes a polícia encaminha o processo ao tribunal, mas o juiz que também recebe dinheiro, vai soltar. O mesmo ladrão sai e volta roubar confiando sempre em pagar (sujeito A2).

A polícia de trânsito na estrada também passa a vida a levar dinheiro dos chapeiros ${ }^{10}$. Mesmo com licença e toda documentação completa, sempre procuram argumentos para extorquir dinheiro (sujeito A3).

\section{Propostas de solução}

Fazer se cumprir a lei contra os corruptos e punir os exemplarmente. Os corruptores também devem ser penalizados (sujeito A1);

O Gabinete de combate contra a corrupção deve sair para as instituições públicas, estradas para identificarem estes casos, ao invés de ficarem nos gabinetes com ar condicionado (sujeito A2);

O povo deve denunciar aos atos de corrupção a quem é de direito. Usar-se as caixas de reclamação instaladas nas instituições públicas para denunciar atos de corrupção (sujeito A3).

\footnotetext{
${ }^{10}$ Chapeiro refere-se ao condutor de Chapa cem. Chapa cem surgiu na década de noventa para designar meios de transporte semicoletivos de passageiros. A designação cem correspondia ao valor que era cobrado pelo transporte, de cem meticais (moeda moçambicana) e era valor único a ser cobrado em todas a rotas. Com a subida e variação do preço dos transportes, desapareceu a palavra cem, ficando apenas chapa.
} 
Dados os problemas e as propostas de soluções apresentadas pelo grupo A, percebeu-se que pela complexidade do próprio tema, os alunos a partir do próprio processo imaginativo quanto aos recursos que o jogo oferece e concomitantemente com as discussões, foram simulando cidades com instituições como escolas, centros de saúde, esquadras policiais, ministérios, entre outras. Na frente dos edifícios colocavam um objeto que no entender dos alunos significava stop corruption (parar com a corrupção). Nas paredes dos edifícios colocavam um outro objeto que no seu entender significava denunciar atos de corrupção. E em todas instituições colocaram uma caixa de reclamação para depositar a denúncia dos atos de corrupção.

Portanto, neste exercício, ficou patente a cooperação entre disciplinas curriculares de Administração Pública, Português, Inglês, entre outras, o que permitiu o aprofundamento das discussões com vista ao processo de produção de sentidos com o simulador Città. Ao mesmo tempo, essa produção de conhecimento, de significações e de sentido, transborda os limites das disciplinas.

A seguir, distingue-se o problema apresentado pelo grupo B.

Quadro 1: Problema e proposta de solução apresentado pelo grupo B da pesquisa

\section{Grupo $B-8^{a}$ classe Sinalização rodoviária nas estradas}

Ao longo das estradas na cidade há défice de sinalização. Por exemplo, alguns semáforos já não funcionam. Outros ainda funcionam com único sinal, por vezes só acende o vermelho ou o verde sem trocar. Alguns entroncamentos nem tem semáforos. Por isso crescem os acidentes de viação cada dia que passa por falta de sinalização (sujeito B1).

Era previsto que perto das escolas tivessem sinais para indicar a aproximação da escola devido a movimentação de alunos. Mas isso não existe. Por exemplo, a Escola Secundária Quisse Mavota está ao longo da Av. Nelson Mandela, mas nos dois sentidos não tem sinalização.

Outro problema está relacionado com as lombas na Av. Nelson. Também não tem nenhuma sinalização da existência de lombas na estrada (sujeito B2).

Em quase toda a cidade não existem passadeiras para peões (pedestres), por isso nós não somos respeitados pelos motoristas. Os atropelamentos nunca param na cidade por este motivo (sujeito B3).

\section{Soluções}

Colocar semáforos em todos os entroncamentos e garantir a sua manutenção periódica. Auxiliar os semáforos com o sinal de STOP (pare) (sujeito B1).

Colocar sinalização a uma distância de aproximadamente 250 metros antes de uma escola, hospital e outros lugares que representam perigo aos motoristas (sujeito B2)

Criar passadeiras para os peões (pedestres) (sujeito B3).

As propostas apresentadas pelo grupo B da pesquisa, mostram mais uma vez a interdisciplinaridade e a transdisciplinaridade feita no trabalho. Aliás, as cidades que 
concomitantemente com as discussões foram simuladas, a partir dos recursos presentes no Città, permitiram que houvesse a cooperação entre diversas disciplinas. Por exemplo, para os alunos colocarem a sinalização rodoviária nas suas cidades simuladas e as narrativas coletivas por eles produzidas, houve uma cooperação entre disciplinas de diversas áreas de conhecimento como o caso de desenho, matemática, inglês, português, entre outras que direta ou indiretamente deram a sua contribuição, como o Guattari nos explica:

As cidades são imensas máquinas com aspectos de infraestrutura, de comunicação e de serviço engendrando por meio de equipamentos materiais e imateriais, a existência humana sob todos os aspetos em que se queira considerá-las. Então, existe uma necessidade de uma colaboração, de uma interdisciplinaridade e transdisciplinaridade entre os urbanistas, os arquitetos e todas outras disciplinas das ciências sociais, das ciências humanas, das ciências ecológicas, etc.... (GUATTARI, 1992, p.82).

Portanto, fica evidente nestes dois exemplos a imaginação dos alunos em "criar-emevento" a partir dos recursos do simulador, propostas de soluções dos problemas que assolam a sua cidade real ou imaginada, aprofundando-as com conhecimentos de diversas áreas disciplinares através de uma inter(trans)disciplinaridade.

\section{Conclusão}

O estudo mostrou como o jogo de construção de cidades Città, apoiado pela metodologia ativa do CIVITAS, pode instigar os alunos a problematizar a realidade na qual estão inseridos, e a partir dos recursos que o jogo apresenta, proporem propostas de soluções cujo os conteúdos discutidos atravessam diversas áreas disciplinares.

Por sua forma de operação, o simulador permite que a produção de narrativas urbanas coletivas relacionadas a um determinado problema ou tema social complexo, seja feita de forma reflexiva, desenvolvendo a capacidade de imaginação e relacionamento de ideias. Contudo, ao invés de centrar-se estritamente na disciplina pertencente ao problema ou tema, o simulador abre espaços para as outras disciplinas cooperarem na obtenção da solução do problema em estudo.

O estudo permitiu concluir que a ferramenta pode ser uma alternativa tecnológica com potencial para fazer um trabalho interdisciplinar e transdisciplinar, quando bem integrada no currículo de educação formal, devido a sua natureza que possibilita resolver problemas ou temas sociais que por serem complexos, não podem ser tradados numa única disciplina. Tal característica permite ao professor reconhecer a necessidade de, não só aprofundar a disciplina, mas de ir além daquilo que já conhece.

\section{Referências}

ALVARENGA, Augusta Thereza de; SOMMERMAN, Américo and ALVAREZ, Aparecida Magali de Souza (2005). Congressos internacionais sobre transdisciplinaridade: reflexões sobre emergências e convergências de ideias na direção de uma nova ciência moderna. Saúde e Sociedade, v. 14, n.3. 


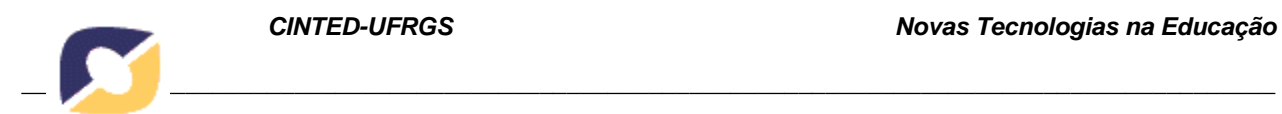

AXT, Margarete (2004). CIVITAS, a Cidade Viva: ou do espaço de invenção do educador na escola.

AXT, Margarete (2011). Mundo da vida e pesquisa em educação: ressonâncias, implicações, replicações. POA, Letras de Hoje, v.46, n.1, p. 46-54.

AXT, M.; KREUTZ, J. R.(2003). Instalando o tempo no espaço social da sala de aula em rede: ou de quando a autoria se (des)dobra em in(ter)venção. In: FONSECA, T. M. G.; KIRST, P. G. Cartografias e devires: a construção do presente. Porto Alegre: Ed. da UFRGS. p. 319-340.

AXT, M., FERREIRA FILHO, R. C. M., BALLE, E. E., MÜLLER, D. N. (2008). Cidades Virtuais: tecnologias para aprendizagem e simulação. IV SEMINÁRIO JOGOS ELETRÔNICOS, EDUCAÇÃO E COMUNICAÇÃO: construindo novas trilhas. Salvador: UNEB, v.1. pp. 1-10.

BAKHTIN, Mikhail Mikhailovich (2003). Estética da Criação Verbal. Tradução do russo Paulo Bezerra. 2. ed. São Paulo: Martins Fontes.

CAESAR. Disponível em: 〈http://www.gamespot.com/caesar-iv/ 〉, acesso em: 16 de maio de 2017

CAPES (2008). Interdisciplinaridade como desafio para o avanço da ciência e tecnologia. Brasília: CAInter/Capes.

CIVITAS - Virtual Cities. Disponível em: <http://sourceforge.net/projects/civitas/ >, acesso em 16 de maio de 2017

FOLLARI, Roberto (1995). Algumas considerações práticas sobre interdisciplinaridade. In: JANTSCH, Ary; BIANCHETTI, Lucídio (orgs). Interdisciplinaridade: para além da filosofia do sujeito. Petrópolis: Vozes.

GUATTARI, Félix (1992). Um novo paradigma estético. Tradução: Ana Lúcia de Oliveira e Lúcia Cláudia Leão. Editora 34 Ltda. Rio de Janeiro.

HUBER, N. (May 2008). Coming Attractions. School Library Journal v. 54 no. 5 p. 38-39.

MÜLLER, Daniel Nehme; QUEVEDO, Laurent Le Avner; NEPOMUCENO, Andressa Cruz;

PROJETO CITTÀ COSMOPOLIA. Disponível em: <http://cosmopolita.conexum.com.br/ >, acesso em: 16 de maio de 2017

SIMCITY. Disponível em: 〈http://www.simcity.com/ >, acesso em: 16 de maio de 2017

SOARES, Luciano; COSTA, Juarez Dubois; SELLI, Maribel Susane; AXT, Margarete (2014).

Relatório Técnico Projeto Città Cosmopolita. CONEXUM Ltda. UFRGS, Porto Alegre.

MÜLLER, D. N.; OLIVEIRA, O. L.; GUIMARÃES, L. N.; SILVEIRA, P. D.; FERREIRA FILHO, R.; AXT, M.(2008). Cidades virtuais como ambiente educacional colaborativo. In: ZAGALO, N. e PRADA, R. ACTAS DA CONFERÊNCIA ZON Digital Games 2008. Centro de Estudos de Comunicação e Sociedade Universidade do Minho. Braga: Zon Multimédia. pp. 123132.

PHARAOH. Disponível em: < http://pharaoh.heavengames.com/ >, acesso em: 16 de maio de 2017 PIAGET, J.(1972). L'épistemologie des relations interdisciplinaires. In APOSTEL, I. et al. L’interdisciplinairé: problemes d'ensignement et de recherche dans les universités. Paris: Ceri/OCDE. p. 131-144. 